\title{
The Stimulated Growth of Tissue Cultured Banana and Slipper Orchid as Exposed to Extremely Low Frequency Electromagnetic Field
}

\author{
Riry Prihatini ${ }^{1 *}$, Norihan M. Saleh ${ }^{2}$ \\ ${ }^{1}$ Indonesian Tropical Fruit Research Institute, Jalan Raya Solok-Aripan km.8 Solok 27301, Sumatera Barat, Indonesia \\ ${ }^{2}$ Department Cell and Molecular Biology, Universiti Putra Malaysia, UPM Serdang 43400, Malaysia
}

Corresponding Author Email: riryprihatini@pertanian.go.id

https://doi.org/10.18280/ijdne.150405

Received: 15 June 2020

Accepted: 20 July 2020

\section{Keywords:}

antioxidant activity, catalase, ELF-EMF, glutathione reductase, in vitro plant, superoxide dismutase

\begin{abstract}
Extremely low frequency electromagnetic field (ELF-EMF) naturally occurs in the environment as the use of electricity become more intense, thus affecting the life of all organisms includes plants, both positive and negative way. The study of to determine the real effect of EFL-EMF was conducted using tissue culture plants in two different plants, banana (Musa acuminata cv. Barangan) and orchid (Paphiopedilum rothscildianum). Banana and orchid plantlets were exposed to 6 and 12 mT ELF-EMF for 0.5, 1, 2, and 4 hours. Four weeks after exposure, the growth and biochemical parameters were investigated. The results showed that $6 \mathrm{mT}$ ELF-EMF had significantly promoted the growth and development of both banana and orchid plantlets for 0.5 and 4 hours duration of exposures, respectively. The long period of exposure of banana plant to ELF-EMF reduced the growth and antioxidant enzyme activities. On the other hand, the orchid exposed to $12 \mathrm{mT}$ ELF-EMF for 4 hours produced the highest shoot number.
\end{abstract}

\section{INTRODUCTION}

The world surround electricity and electric equipments emit another natural force which is called as electromagnetic field. The range of electromagnetic is define by the frequency of electricity waves, the lowest range frequency is $3-3000 \mathrm{~Hz}$ electromagnetic field is known as extremely low frequency electromagnetic field (ELF-EMF) [1]. The household electricity and power lines are having 50 or $60 \mathrm{~Hz}$ frequency in the Europe and USA regions, respectively, thus constantly release the ELF-EMF. The modern life applies electricity in almost all aspects and consequently the exposure of ELF-EMF to living organisms is always present [2].

The effect of ELF-EMF on human health and animal becomes a hot topic for many researches for the past 20 years. It is revealed that ELF-EMF may have a positive and negative impact on human. ELF-EMF may both stimulatory and inhibitory effects on immune system response [3]. It is also reported that ELF-EMF lessen oxidative stress and enhanced patient physiological and functional status [4], while in Escherichia coli, the exposure to EFLM-EMF induce growth of the bacteria [5].

Similarly, some research in extremelylow frequency electromagnetic field (ELF-EMF) exposure to plant, may induce positive effects on plants [6].These results include increasing seed germination percentages of cucumber (Cucumis sativus) [7] and mung bean [8], and increasing a number of shoot germination of in vitro plum (Prunus maritime) [9], and herbs Urtica dioica [10], maize [11]. These results implying that the positive effects of ELF-EMF exposures on plants growth may cause by the increment of antioxidant enzymes activities, such as catalase (CAT), superoxide dismutase (SOD), and glutathione reductase (GR) [7]. Another possible mechanism of ELF-EMF exposure promoting seed germination is by generating alteration of membrane transport process in root tips, and thus increasing the root's amino acid uptake [12]. Another study implied that exposure to ELF-EMF promotes the content of calcium and potassium ion in mung bean seedling [13]. The recent study concluded that the ELF-EMF exposure may be use as friendly method to improve crops growth and germination [14].

Most studies on the impacts of ELF-EMF on various crop plants have been conducted using seeds and native plants which are grown under natural condition. However, it is difficult to measure the true impacts of ELF-EMF on these plants since other abiotic factors, such as climate, soil, and light may contribute to the measurement. In order to eliminate these factors and determine the true impacts of ELF-EMF on the plants, in vitro culture system was selected for this research.

Biochemical properties that were usually measured to determine the growth and development in in vitro plant study include total soluble protein [15-17]. and antioxidant enzyme activities (i.e. catalase, ascorbate peroxidase, superoxide dismutase, and glutathione) $[15,17,18]$.

Banana (Musa acuminta cv. Barangan) and slipper orchid (Paphiopedilum rothscildianum) are commercial monocotyledone which are values for the fruits and flowers, respectively. These crops usually propagate through in vitro culture since the technique may facilitate to produce mass seedling within the relatively short time compare to the conventional propagation. Thus, the plants are chosen to investigate the effect ELF-EMF on the in vitro growth.

In brief, our experiment showed positive effects of ELFEMF on the in vitro growth of banana and orchid. Both species required certain amount of ELF-EMF exposure to produced better performance compared to the control group. The results also suggest a potential of the ELF-EMF exposure in supporting of plant tissue culture technology. 


\section{MATERIALS AND METHODS}

\subsection{Plant materials, ELM-EMF exposure to plant materials, and culture condition}

The corm banana (Musa acuminate cv. Berangan) explants ( $1 \mathrm{~cm}$, obtained from 8 weeks old plantlets) were cut under sterile condition and cultured for 4 days on a modified MS [19] medium prior to exposure to ELF-EMF. For this study, the orchid mother plants were derived from established in vitro culture of $P$. rothscildianum. A single bud (with 3 leaves and $0.5 \mathrm{~g}$ of weight) was used as explants for the treatment. The explants were cultured on a modified $1 / 2 \mathrm{MS}$ medium for 7 days prior to exposure to ELF-EMF.

The CoGEM 1000 [20] was used to produce uniform and stabile ELF-EMF. Four days old banana and seven days old orchid (after subculture) were placed in each vessel (a diameter of $7 \mathrm{~cm}$ and height of $12 \mathrm{~cm}$ ). The in vitro cultures were then subjected to two different strengths of ELF-EMF (6 and $12 \mathrm{mT})$ at four different durations of exposure $(0.5,1,2$, and 4 hours).

After the exposure, the in vitro cultures were incubated in the growth chamber with a $16 \mathrm{~h}$ photoperiod at $25^{\circ} \mathrm{C}$. Due to a different growth rate, different plant species were incubated at different durations, viz. 4 weeks for banana and 16 weeks for orchid.

\subsection{Growth parameters}

In the two monocot plants used in this study, the growth of banana plant was determined by the number of shoots and shoots height, but in the slipper orchid plant, its growth was determined by observing the number of shoots and the number of leaves formed.

\subsection{Biochemical parameters}

The total soluble protein content was analyzed using Bradford method [21]. The catalase (CAT), ascorbate peroxidase (APX), superoxide dismustase (SOD), and glutathione reductase (GR) enzyme activities were determined using the spectrophotometry method suggested previously [22-24].

\subsection{Experimental design and statistical analysis}

All in vitro experiments were arranged in Randomly Complete Block Design (RCBD) which included 8 treatments and one control. There were 10 samples on each treatment for banana and 20 samples on each treatment for slipper orchid. The whole experiments were replicated three times. The data were analyzed using multivariate analysis of variance
(MANOVA) that was based on Willks's Lambda to identify the significance between groups of treatment $(P<0.05)$. All statistical analyses were done using computer software of SPSS ver. 18.0 (SPSS).

\section{RESULTS AND DISCUSSION}

\subsection{Effects of ELF-EMF on the growth and biochemical characteristics of the tissue cultured banana plants}

The MANOVA analysis for the effects of ELF-EMF on the developmental parameters of banana plantlets indicated that different strength and duration exposures to ELF-EMF had significantly affected $(P<0.05)$ the shoot height parameter of the banana (Table 1 ).

The statistical analysis revealed that interaction between ELF-EMF strength and duration of exposure significantly affected plant growth parameter both in banana and orchid. Furthermore, the MANOVA also illustrated that the ELFEMF exposure affected the biochemical properties of the observed plants. In details, the ELF-EMF exposure on banana induced different number of shoots, shoot height, total soluble protein, CAT, APX, SOD, and GR enzymes activities. In addition, for orchid the ELF-EMF produced different number of shoots and leaves, total soluble protein, CAT, APX, SOD, and GR enzymes activities of the treated plants compared to the control group.

The exposure to the $6 \mathrm{mT}$ ELF-EMF for 0.5 hours resulted in the number of shoots $(1.4 \pm 0.1)$, meaning that the shoot growth increased by $27.3 \%$. The MANOVA also showed that the exposure to the $12 \mathrm{mT}$ ELF-EMF for 2 hours had significantly increased the banana shoot height by $44.9 \%$ (7.3 $\pm 0.3 \mathrm{~cm}$ ) (Figure 1).

The multiple shoots (more than one) induced on banana plantlets exposed to $6 \mathrm{mT}$ ELF-EMF for 0.5 hours occurred on 16 out of 30 banana cultures exposed to this treatment and none from other group of treatments. Nonetheless the multiple shoots induced showed a lower height compared to the single shoot induced. It was also revealed that the increment of shoot height on cultures that had been exposed to the ELF-EMF was fluctuating. It might be suggested by the findings that ELFEMF strength and duration of exposure had an interaction effect on the plant. The ELF-EMF strength had to be interacted with the precise exposure duration of exposure to produce a positive response from the banana cultures. Similar results had been shown on Prunus maritima, in which higher ELF-EMF strength increased the shoot number of the in vitro plants. In this study, the exposure to $97 \mathrm{kA} / \mathrm{m}$ (equivalent to $60 \mathrm{mT}$ ) for short duration (10 minutes) of ELF- EMF increased the number of shoots by $200 \%$ [9].

Table 1. The Multivariate analysis of variance (MANOVA) of the effect of different strength and duration exposre to the ELFEMF (Extremely Low Frequency Electromagnetic Field) on the developmental and biochemical parameters of the tissue cultured banana and slipper orchid plantlets

\begin{tabular}{cccc}
\hline Manova result & \multicolumn{2}{c}{ Banana } & \multicolumn{2}{c}{ Slipper orchid } \\
& Growth parameter & Biochemical parameters & Growth parameters \\
Biochemical parameters
\end{tabular}




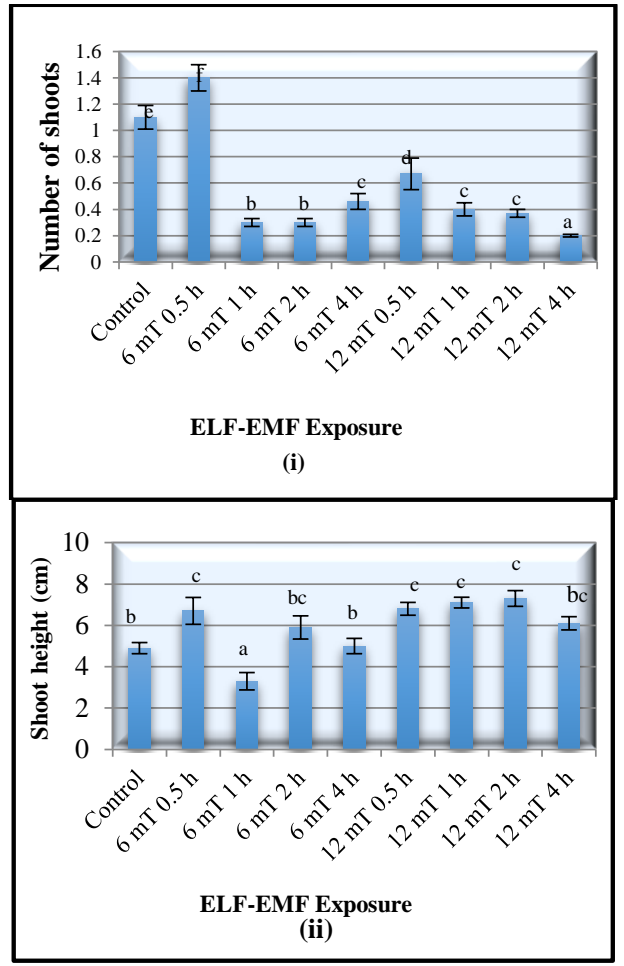

(i) shoots number and (ii) shoot height cultures (mean \pm standard error followed by the same letter are not significantly different from each other according to Duncan's multiple range test at $P=0.05$ )

Figure 1. Effect of different strength and duration exposure to ELF-EMF (extremely low frequency electromagnetic field) on the developmental characteristics of the tissue cultured banana plantlets 8 weeks after treatment

The MANOVA test for the effect of ELF-EMF exposures on the biochemical properties of tissue cultured banana plantlets showed that the different strength and duration of ELF-EMF had a significant effect on all biochemical parameters that were tested. An exposure to the $6 \mathrm{mT}$ ELFEMF for 0.5 hours had also resulted in the highest production in the plant total soluble protein content $(23.8 \pm 1.69 \mathrm{mg} / \mathrm{g})$ or $97.5 \%$ higher than the control group (Figure 2).

In addition, the control group had the highest SOD enzyme activity $(1.54 \pm 0.09$ units $/ \mathrm{mg})$ the highest APX enzyme activity $(26.15 \pm 2.21$ units $/ \mathrm{mg})$. The exposure to the $6 \mathrm{mT}$ ELF-EMF for 0.5 hour had decreased the APX enzyme activity by $69 \%$. Doubling the duration exposure to the same ELF-EMF strength had the lowest SOD enzyme activity which was $66.7 \%$ lower than control. However, there were no significant changes in activity of GR in the presence of ELFEMF (Figure 2).

The APX and SOD are responsible for major ROSscavenging mechanisms of the plant. The balance activity between SOD and CAT or APX is crucial to prevent the formation of highly toxic molecules. The plants that have suppression of APX production induced more CAT and SOD to balance the decrease of the APX in plant [18]. Moreover, in banana plants, peroxidase plays an important role on defence system against a biotic stress. Musa sp. cultivar Calcutta, a black leaf streak disease resistant banana, proved to have high peroxidase enzyme activities compared to the Musa sp. cultivar Grand Naine and Pisang Madu. Both cultivars were susceptible and partially resistant, respectively, to the disease [25].

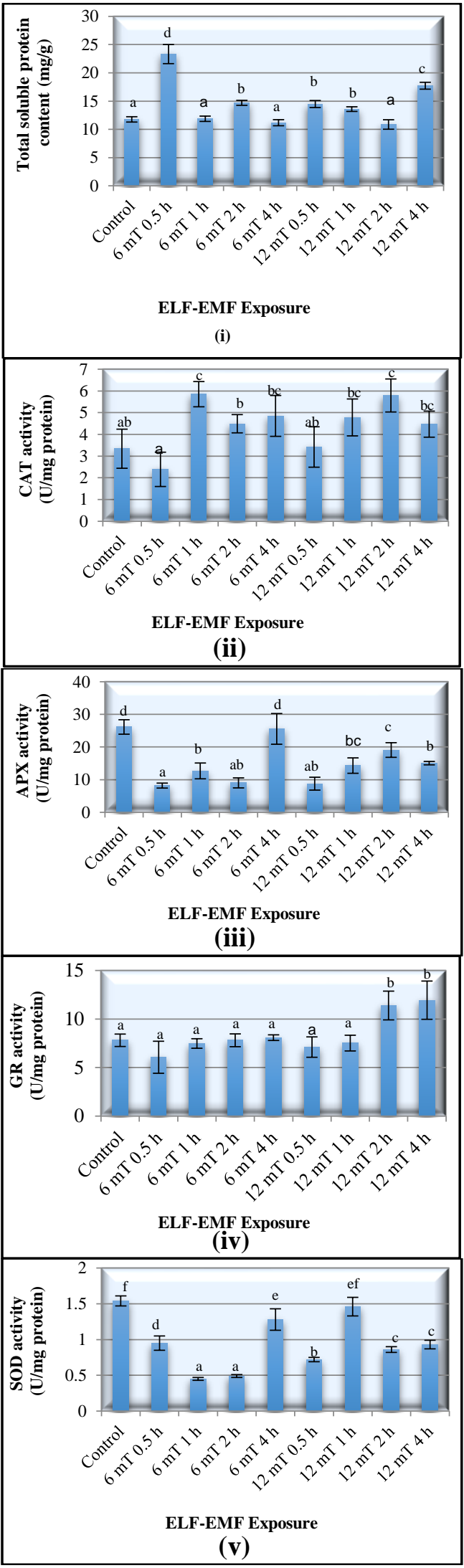

(i) total soluble protein, (ii) catalase, (iii) ascorbate peroxidase, (iv) glutathione reductase, and (v) superoxide dismutase enzymes activities (mean \pm standard error followed by the same letter are not significantly different from each other according to Duncan's multiple range test at $P=$ $0.05)$

Figure 2. Effect of different strength of duration exposure to ELF-EMF (extremely low frequency electromagnetic field) on the biochemical properties of the tissue cultured banana plantlets 8 weeks after treatment 
Similarly infection by fungi, Fusarium also increases antioxidant activities in banana [26]. The increase in antioxidant activity also occurs when the plats were exposed to salinity and other abiotic stress [27]. On the molecular aspect, the abiotic stress may be regulated by the cystolic ascorbate peroxidase gene as shown ectopically in transgenic Grand Naine banana [28].

The decrease of SOD enzyme activity had been reported in the tobacco cell suspension culture when it was exposed to higher magnetic field (10 and $30 \mathrm{mT}$ ) for longer duration of exposure ( 5 hours per day, for 5 days). It was also suggested that the inability of the plant to produce more SOD and GR enzymes when exposed to the higher ELF-EMF strength and longer duration of ELF-EMF exposure had caused the plant failed to detoxify toxic reactive oxygen species [29].

The fluctuate results of all biochemical parameters that were tested in banana exposed to the ELF-EMF might be due to variation in the genotype which caused by somaclonal variation. Although the banana explants used in this study had the same age (5 weeks old), since the plantlets were obtained from commercial tissue culture laboratory, it was hard to determine if the plantlets came from the same source of explants. Furthermore, it was also intricate to find out if the plantlets came from the same batch of multiplication; since number of subcultures was also a source of somaclonal variation [30]. Somaclonal variation is a common phenomenon that occurs in the banana tissue culture especially one with the polyploidy cultivar, such as Barangan (AAA) [31]. The somaclonal variation induced in in vitro culture influenced mitotic instability especially in regenerate abnormal metaphase [32]. The variation occurs in banana tissue culture includes changes in biochemical parameters, such as chlorophyll content and enzyme activities [33]. Genetic variation caused by in vitro culture activity may be a decent source in banana improvement program.

\subsection{Effects of the ELF-EMF on the growth and biochemical characteristics of the tissue cultured slipper orchid}

The MANOVA result for the effects of the ELF-EMF on the developmental parameters of the tissue cultures slipper orchid plantlets revealed that the different strength and duration of ELF-EMF exposure had significantly affect number of shoots and number of leaves. The exposure to $12 \mathrm{mT}$ ELF-EMF for 4 hours had resulted in the formation of the highest number of shoots $(3.6 \pm 0.2)$ and leaves $(10.1 \pm 0.4)$ (Figure 3$)$. The exposure to ELF-EMF to the slipper orchid increased the number of shoots and leaves by $56 \%$ and $41.9 \%$, respectively.

Although the multiple shoots induce in almost all groups, but the cultures group exposed to $12 \mathrm{mT}$ ELF-EMF for 4 hours showed multiple shoot growth in 60 out of 60 exposed plantlets. The range of multiple shoots induced on this group was 2 to 6 shoots per explants; whereas in other group the shoots induced were range from 1-3 shoots per explants. Nonetheless, the extended duration of the same ELF-EMF strength (an exposure to the $12 \mathrm{mT}$ ELF-EMF for 8 hours) significantly reduced number of shoots induced, yet the values were still higher than the values of the control plant (the data are not shown). The significance increase of shoot growth of the ELF-EMF exposed slipper orchid was a result of higher rate of cell division, cell extension, and cell differentiation. It was suggested that ELF-EMF exposures stimulated the cell growth; thus, resulted in promoted plants growth [9]. Another possible mechanism of increase plant growth after exposing to
ELF-EMF was because the ELF-EMF changed the cell ionic concentration and osmotic pressure; thus, provide suitable environment for the optimum ionic transport and water across the cell membrane $[8,13]$.

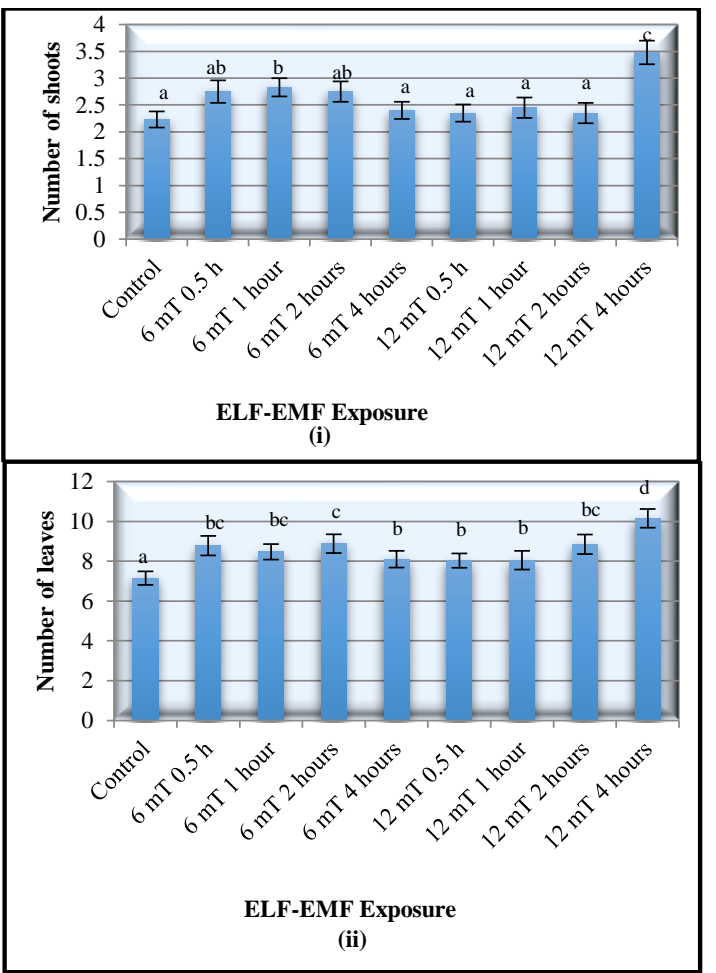

(i) number of shoots and (ii) number of leaves (mean \pm standard error followed by the same letter are not significantly different from each other according to Duncan's multiple range test at $P=0.05$ )

Figure 3. Effect of different strength and duration exposure to ELF-EMF (extremely low frequency electromagnetic field) on the developmental characteristics of the tissue cultured slipper orchid plantlets 16 weeks after treatment

The longer duration of ELF-EMF exposure (more than 4 hours) had a limited positive effect compared to $12 \mathrm{mT} 4$ hours treatment on the slipper orchid growth. Similar results have been observed in the tissue cultured banana. The increase in the number of shoots in orchid (Oncidium taka PLBs; protocorm-like bodies) had also been reported in the presence of $40 \mathrm{kV} / \mathrm{m}$ electric fields strength [34] where it increased the growth of the orchid. However, the study of the effects of electric field on the orchid did not measure the strength of ELF-EMF that might be occurring in their research.

Paphiopedilum rothschildianum commonly propagate through tissue culture since the plant is categorized as endangered species by the Convention Trade in Endangered Species of Wild Fauna and Flora (CITES) in order to reintroduce the plant [35]. In this study, the ELF-EMF exposure produces 3.6 of shoots per explants. This number is higher than the maximum number shoots per explants that had been reported before which was 2.9 shoots per explants [36]. It is demonstrated that the exposure to the ELF-EMF had a promising application to increase the shoot number induction of $P$. rothschildianum.

Further analyses of the MANOVA on the effect of ELFEMF exposure on the biochemical properties of the slipper orchid illustrated that the exposure to ELF-EMF significantly $(P<0.05)$ (Table 1$)$ had an effect on all biochemical parameters, including total soluble protein content, CAT, APX, SOD, and GR enzymes activities. 


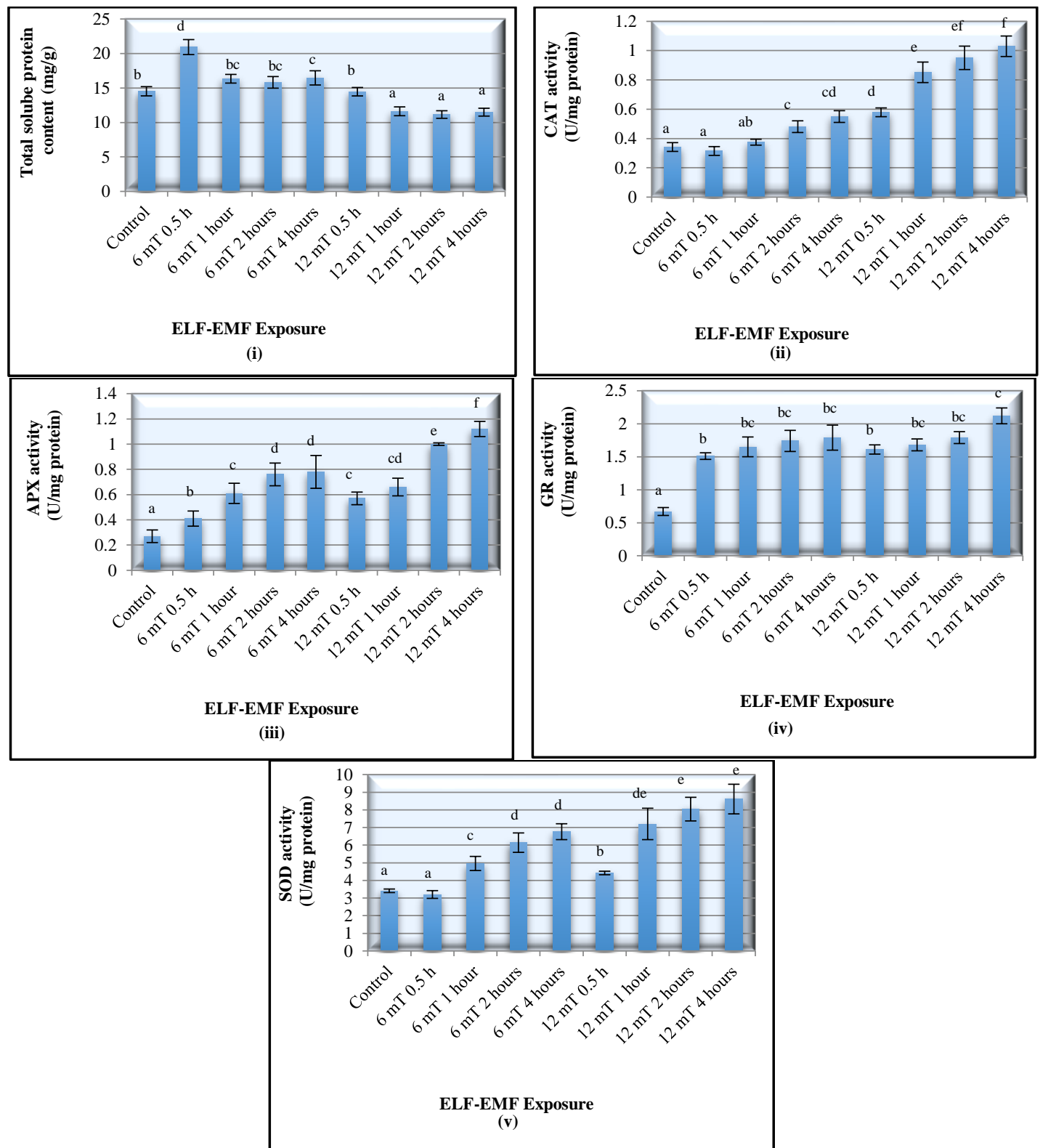

(i) total soluble protein (mg/g), (ii) catalase enzyme activity (U/mg), (iii) ascorbate peroxidase enzyme activity (U/mg), (iv) glutathione reductase enzyme activity $(\mathrm{U} / \mathrm{mg})$, and (v) superoxide dismutase enzymes activity $(\mathrm{U} / \mathrm{mg})$ (mean \pm standard error followed by the same letter are not significantly different from each other according to Duncan's multiple range test at $P=0.05$ )

Figure 4. Effect of different strength and duration exposure to ELF-EMF (extremely low frequency electromagnetic field) on the biochemical properties of the tissue cultured slipper orchid plantlets 16 weeks after treatment

The exposure of orchid plants to $12 \mathrm{mT}$ ELF-EMF for 4 hours had resulted in the highest activities of the CAT (1.0 $\mathrm{U} / \mathrm{mg}$ protein), APX (1.12 $\pm 0.06 \mathrm{U} / \mathrm{mg}$ protein $), \mathrm{SOD}(2.12 \pm$ $0.12 \mathrm{U} / \mathrm{mg}$ protein), and GR $(8.61 \pm 0.84 \mathrm{U} / \mathrm{mg}$ protein $)$ (Figure 4). This exposure had significantly increased the CAT, APX, SOD, and GR activities for $233.3 \%, 314.8 \%, 216.4 \%$, and $152.5 \%$; respectively (Figure 4.). It was also demonstrated that the CAT activity significantly increased with the increase of ELF-EMF strength and duration of exposure.

Overall, the data obtained revealed that the exposure to the $12 \mathrm{mT}$ ELF-EMF for 4 hours had resulted in the highest number of shoots, leaves, and also the antioxidant enzymes activities. High activity of antioxidant enzyme showed a high elimination rate of the toxic hydrogen peroxide into oxygen. Therefore, it is suggested that the slipper orchid required high activity of CAT, APX, SOD, and GR in order to be able to produce the optimum growth after exposed to ELF-EMF. The high of antioxidant activity is required to combat the toxic reactive oxygen species that emerge in the environment [37]. A similar phenomenon on the increased of antioxidant activity occur on orchid which is exposed to other abiotic stress as a result of molecular intervention [38].

In the presence of abiotic stress and high concentration of reactive oxygen species (ROS), the cellular activity of the plant will be stimulated to enhance the activities of some antioxidative enzymes in order to scavenge the ROS. This phenomenon had been observed in this study on selected plant species. The catalase enzyme (CAT) which play a role in catalyzing the decomposition of $\mathrm{H}_{2} \mathrm{O}_{2}$ into water and oxygen, was significantly increased in all tested plants (banana and orchid) when 6 and $12 \mathrm{mT}$ ELF-EMF were applied to the plants. Only orchid showed an increased in the SOD enzyme activities which catalyzed the destructive superoxide radicals.

Significant increase in GR was also observed in banana which is facilitated plants to reduce toxicity level due to the presence of $\mathrm{H}_{2} \mathrm{O}_{2}$. In addition, the APX enzyme activity was 
increased in orchid. Hence, it can be summarized that the tolerance level of plants to ELF-EMF was genotype dependent; where banana seems to be more sensitive than the orchid plants tested.

As ELF-EMF occurred in the environment, it becomes natural forces to all organisms, includes plant, animal, and also human. For some cases, the ELF-EMF exposure may induce positive effects as illustrated in this present research. The potential used of ELF-EMF exposure in micropropagation may be applied to replace the use of high concentration of plant growth regulators (PGR). In conventional plant tissue culture, the use of PGR may cause somaclonal variation. Hence, the application of ELF-EMF to replace the use of PGR should also be evaluated in term of somaclonal variation frequencies of the plantlets.

\section{CONCLUSION}

In general, ELF-EMF exposure to in vitro banana and orchid produced positive effects on plants growth such as induced more shoots number than the unexposed plants. The increase of antioxidants activities in ELF-EMF exposed plants suggested the ability of plants to combat ROS which is may be occurred on the in vitro environment as a result of ELF-EMF exposure. These results implied a potential application of ELFEMF exposure to stimulate growth of in vitro plants culture technologies especially for micropropagation purpose.

\section{REFERENCES}

[1] Poole, C., Ozonoff, D. (1996). Magnetic field and childhood cancers. IEEE Engineering Medical Biology, 15(4): 41-49. https://doi.org/10.1109/51.511981

[2] D'Angelo, C., Constantini, E., Kamal, M.A., Reale, M. (2015). Experimental model for ELF-EMF exposure: Concern for human health. Saudi Journal of Biological Sciences, 22(1): 75-84 https://doi.org/10.1016/j.sjbs.2014.07.006

[3] Mahaki, H., Tandazehpanah, H., Jabarivasal, N., Sardanian, K., Zamani, A. (2019). A review on the effects of extremely low frequency electromagnetic field (ELF-EMF) on cytokines of innate and adaptive immunity. Electromagnetic Biology and Medicine, 38(1): 84-95. https://doi.org/10.1080/15368378.2018.1545668

[4] Cichon, N., Bijak, M., Miller, E., Saluk, J. (2017). Extremely low frequency electromagnetic field (ELFEMF) reduces oxidative stress and improves functional and physiological status in ischemic stroke patients. Bioelectromagnetics, 386(5): 396. https://doi.org/10.1002/bem.22055

[5] Chen, Y., Chain, Z., Feng, Q., Gao, P., Yang, Y., Bai, X., Tang, B.Q., Zang, T. (2019). Evaluation of the extremely low frequency electromagnetic field (ELF-EMF) on the growth of bacteria Escherichia coli. Cogent Biology, $5(1)$ : 1625104. https://doi.org/10.1080/23312025.2019.1625104

[6] Nyakane, N.E., Markus, E.D., Sedibe, E.E. (2019). The effects of magnetic fields on plants growth: A comprehensive review. International Journal of Food Engineering, 5(1): 79-87. https://doi.org/10.18178/ijfe.5.1.79-87

[7] Piacentini, M.P., Fraternale, D., Piatti, E., Ricci, D.,
Vetrano, F., Dacha, M., Accorsi, A. (2001). Senescence delay and change of antioxidant enzyme levels in Cucumis sativus L. etiolated seedlings by ELF magnetic fields. Plant Sciences,161(1): 45-53. https://doi.org/10.1016/S0168-9452(01)00380-6

[8] Huang, H.H., Wang, S.R. (2007). The effects of $60 \mathrm{~Hz}$ magnetic fields on plant growth. Nature and Science, 5(1): 59-68.

[9] Yan, D.L., Guo, Y.Q., Zai, X.M., Wan, S.W., Pei, Q. (2009). Effect of electromagnetic fields exposure on rapid micropropagation of beach plum (Prunus maritima). Ecological Engineering, 35(4): 597-601. https://doi.org/10.1016/j.ecoleng.2008.04.017

[10] Rostami, Z.E., Majd, A., Arbabian, S. (2014). Effects of electromagnetic fields on seed germination in Urtica Dioica L. International Journal of Scientific \& Technology Research, 3(4): 365-368.

[11] Isaac, E.A., Hernández, C.A., Domínguez, A.P., Cruz, A.O. (2011). Effect of pre-sowing electromagnetic treatment on seed germination and seedling growth in maize (Zea mays L.). Agronomía Colombiana, 29(2): 213-220.

[12] Stange, B.C., Rowland, R.E., Rapley, B.I., Podd, J.P. (2003). ELF magnetic fields increase amino acid uptake into Vicia faba L. roots and alter ion movement across the plasma membrane. Bioelectromagnetics, 23(5): 347354. https://doi.org/10.1002/bem.10026

[13] Huang, P., Tang, J., Feng, C., Jang, L. (2018). Influences of extremely low frequency electromagnetic field on germination and early growth of mung bean. IEEE International Conference on Consumers ElectronicsTaiwan (ICCE-TW), Taichung, pp. 1-2. https://doi.org/10.1109/ICCE-China.2018.8448809

[14] Bisceglia, B., Valbonesi, S. (2017). ELF field in agriculture: New techniques for a sustainable development. International Applied Computational Electromagnetics Society Symposium- Italy (ACES), Florence, Italy, pp. 1-2. https://doi.org/10.23919/ROPACES.2017.7916415

[15] Lombardi, L., Sebastini, L. (2005). Copper toxicity in Prunus cerasifera: Growth and antioxidant enzymes responses of in vitro grown plants. Plant Science, 168(3): 797-802. https://doi.org/10.1016/j.plantsci.2004.10.012

[16] Amini, F., Ehsanpour, A.A. (2005). Soluble Proteins, proline, carbohydrates and $\mathrm{Na}+\mathrm{K}+$ changes in two tomato (Lycopersicon esculentum Mill.) cultivars under in vitro salt stress. American Journal of Biochemistry and Biotechnology, 1(4): 204-208. https://doi.org/10.3844/ajbbsp.2005.212.216

[17] Niknam, V., Rajavi, N., Ebrahimzadeh, H., Sharifizadeh, B. (2006). Effect of $\mathrm{NaCl}$ on biomass, protein and proline contents, and antioxidant enzymes in seedlings and calli of two Trigonella species. Biologia Plantarum, 50: 591596. https://doi.org/10.1007/s10535-006-0093-2

[18] Meratan, A.A., Ghaffari, S.M., Niknam, V. (2009). In vitro organogenesis and antioxidant enzymes activity in Acanthophyllum sordidum. Biologia Plantarum, 53: 5-10. https://doi.org/10.1007/s10535-009-0002-6

[19] Murashige, T., Skoog, F. (1962). A revised medium for rapid growth and bioassays for tobacco tissue cultures. Physiologia Plantarum, 15: 473-497.

[20] Prihatini, R., Abdullah, M.P., Abdullah, T.A.R.T., Said, I., Hussin, H., Saleh, N.M. (2017). Extremely low frequency electromagnetic field generator suitable for 
plant in vitro studies. Research in Agricultural Engineering, 63: 180-186. https://doi.org/10.17221/47/2016-RAE.

[21] Bradford, M.M. (1976). A rapid and sensitive for the quantification of microgram quantities of protein utilizing the principle of protein-dye binding. Analytical Biochemistry, 72:

248-254. https://doi.org/10.1006/abio.1976.9999

[22] Bergmeyer, N. (1970). Methoden der enzymatischen. Analyse Volume I. Akademie Verlag, Berlin, 636-647.

[23] Nakano, Y., Asada, K. (1981). Hydrogen peroxide is scavenged by ascorbate-specific peroxidase in spinach chloroplast. Plant Cell Physiology, 22(5): 867-880. https://doi.org/10.1093/oxfordjournals.pcp.a076232

[24] Elavarthi, S., Martin, B. (2010). Spectrophotometric assays for antioxidant enzymes in plants. In: Sunkar R. (eds) Plant Stress Tolerance. Methods in Molecular Biology (Methods and Protocols), vol 639. Humana Press. https://doi.org/10.1007/978-1-60761-702-0_16

[25] Cavalcante, M.J.B., Escoute, J., Madeira, J.P., Romero, R.E., Nicole, M.R., Oliveira, L.C., Hamelin, C., Lartaud, M., Verdeil, J.L. (2011). Reactive oxygen species and cellular interactions between Mycosphaerella fijiensis and banana. Tropical Plant Biology, 4(2): 134-143. https://doi.org/10.1007/s12042-011-9071-8

[26] Anthony, K.K., George, D.S., Singh, H.K.B., Fung, S.M., Santhiraseragam, V., Razali, Z., Somasundram, C. (2017). Reactive oxygen species activity and antioxidant properties of Fusarium infected bananas. Journal of Phytopathology, $165(4)$ https://doi.org/10.1111/jph.12552

[27] Mazumdar, P., Lau, S., Singh, P., Takhtgahi, H.M., Harikrishna, J.A. (2019). Impact of sea-salt on morphophysiological and biochemical responses in banana (Musa acuminata cv. Berangan). Physiology and Molecular Biology and Plants, 25: 713-726. https://doi.org/10007/s12298-019-00659-3

[28] Shekhar, S., Rustagi, A., Kumar, D., Yusuf, M.A., Sarin, N.B., Lawrence, K. (2019). Groundnut AhcAPX conferred abiotic stress tolerance in transgenic banana through modulation of the ascorbate-glutathione pathway. Physiology and Molecular Biology of Plants, 25(6): 1349-1366. https://doi.org/10.1007/s12298-01900704-1

[29] Sahebjemai, H., Abdolmaleki, P., Ghanati, F. (2007). Effect of magnetic field on the antioxidant enzyme activities of suspension-cultured tobacco cells. Bioelectromagnetics, $28(1)$ : 42-47. https://doi.org/10.1002/bem.20262

[30] Nwauzoma, A.B., Jaja, T.T. (2013). A review of somaclonal variation in plantain (Musa spp): mechanisms and applications. Journal of Application Bioscience, 67 https://doi.org/10.4314/jab.v67i0.95046

[31] Bidabadi, S.S., Meon, S., Wahab, Z., Mahmood, M. (2010). Study of genetic and phenotypic variability among somaclones induced by BAP and TDZ in micropropagated shoot tips banana (Musa spp.) using RAPD markers. Journal of Agriculture Science, 2: 49-60. https://doi.org/10.5539/jas.v2n3p49

[32] Moradi, Z., Farahani, F., Sheidai, S., Satari, T.N. (2017). Somaclonal variation in banana (Musa acuminata colla cv. Valery) regenerated plantlets fromsomatic embryogenesis: histological and cytogenetic approaches. International Journal of Cytology, Cytosysteatics and Cytogenetics, 70(1): 1-6. https://doi.org/10.1080/00087114.2016.1198665

[33] Bairu, M.W., Aremu, A.O., Van Staden, J. (2011). Somaclonal variation in plants: Causes and detection methods. Plant Growth Regulation, 63: 147-173. https://doi.org/10.1007/s10725-010-9554-X

[34] Mahmood, M., Ooi, B.B., Mahmud, T., Subramaniam, S. (2011). The growth and biochemical responses on in vitro cultures of Oncidium taka orchid to electromagnetic field. Australian Journal of Crop Science, 5(12): 1577 1587.

[35] Zeng, S.J., Wu, K.L., da Silva, T.J.A., Zhang, J.X., Chen, Z.L., Xia, N.H., Duan, J. (2012). Asymbiotic seed germination, seedling development, and reintroduction of Paphiopedilum wardii Sumerh., an endangered terrestrial orchid. Scientia Horticulturae, 138: 198-209. https://doi.org/10.1016/j.scienta.2012.02.026

[36] Ng, C.H., Saleh, N.M., Zaman, F.Q. (2010). In vitro multiplication of the rare and endangered slipper orchid, Paphiopedilum rothschildianum (Orchidaceae). African Journal of Biotechnology, 9(14): 2062-2068.

[37] Ping, K.S., Zakaria, R., Subramanian, S. (2016). Ascorbate peroxidase activity of Aranda Broga Blue Orchid protocorm-like bodies (PLBs) in response to PVS2 cryopreservation methods. Tropical Life Science Research, 27(1):

139-143. https://doi.org/10.21315/tlsr2016.27.3.19

[38] Sembi, J.K., Ghai, D., Vrma, J. (2019). Molecular intervention to ameliorate environmental stress in orchids. In: Singh, S., Upadhyay, S., Pandet, A., Kumar, S. (eds.). Molecular approaches in plant biology and environmental challenges, energy, environment, and Sustainability, Springer, Singapore, pp. 449-474. https://doi.org/10.1007/978-981-15-0690-1_20 